\title{
O ensino de cartografia para alunos com deficiência visual
}

\section{The teaching of cartografy to students with visual deficiency}

Mariluze de Carvalho Campos *

\section{Resumo:}

A Geografia é uma disciplina que tem como suporte os recursos cartográficos e, dependendo como forem trabalhados e utilizados, podem possibilitar aos discentes uma melhor compreensão quanto às diversas representações do espaço geográfico. No entanto, no que diz respeito aos alunos com Deficiência Visual, tais recursos precisam ser reformulados e adaptados, necessitando, ainda, que os professores da disciplina em foco, propiciem atividades de estimulação tátil visando desenvolver, gradativamente, esse sentido. Nesse viés, esse artigo foi elaborado com o objetivo de indicar propostas de atividades direcionadas aos alunos que possuem esse tipo de deficiência, tendo como peças centrais os recursos táteis, perpassando ainda pelas leis que asseguram os direitos desses cidadãos. Para o alcance desse objetivo, foi feita uma pesquisa em livros, leis, revistas, sites, artigos, a fim de embasar o trabalho de um modo geral. Pretende, por fim, apresentar a importância da Cartografia Tátil como uma ferramenta capaz de fornecer um maior conhecimento da organização e distribuição dos seus espaços de vivência e enfatizar o quanto é essencial a ampliação das discussões voltadas para tal.

\begin{abstract}
:
The Geography is an important subject that allows every student to better understand the several representations of the geographical area through cartographic resources. Nevertheless, when we deal with Visual Deficiency, these resources must be reformulated and adjusted. The teachers have to provide special activities in order to stimulate and gradually develop the tactile sense. To achieve this objective, a survey was made in books, laws, magazines, websites, articles in order to base the work in general. In this direction, this article aims to propose tactile activities for students who own this kind of the Tactile Cartography as a tool able to provide more knowledge of its organization and distribution of its areas and emphasize how much this kind of discussion is essential.
\end{abstract}

* Graduada em Geografia pela Universidade do Estado da Bahia (UNEB), com especialização em Ensino de Geografia pelo Instituto PróSaber. Pós Graduanda em Educação, Contemporaneidade e Novas Tecnologias pela Universidade do Vale do São Francisco (UNIVASF).

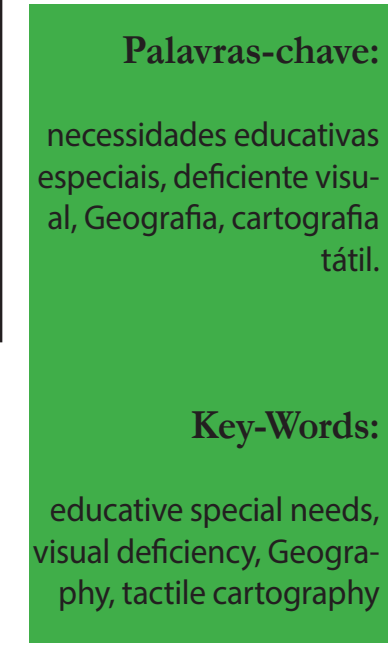




\section{INTRODUÇÃO}

Presente trabalho surge do desejo de contribuir para o ensino de Geografia voltado para os deficientes visuais, na intenção de facilitar a compreensão dos mesmos em relação à noção e a dimensão dos seus espaços cotidianos. Por isso, faz-se necessário entender a forma com que a Cartografia pode auxiliar na ampliação dessa possibilidade por meio do ramo da Cartografia Tátil, sendo ela responsável pela elaboração de recursos para serem utilizados pelas pessoas que possuem esse tipo de deficiência. Para que o alcance desse objetivo, foi preciso fazer várias pesquisas em livros, leis, revistas, sites, artigos e, apesar das restrições de informações encontradas, os materiais adquiridos permitiram dar certo embasamento sobre a temática.

É fundamental deixar claro também, que, mesmo especificando e enfatizando apenas a Deficiência Visual com foco no trabalho com alunos cegos, tem-se a consciência da importância dos trabalhos voltados para todo e qualquer tipo de deficiência, podendo assim, ampliar as discussões e contribuir para que esses indivíduos possam ter uma significativa aprendizagem.

\section{PARA INIICIO DE CONVERSA}

A inclusão/exclusão de deficientes nas escolas brasileiras sejam eles físicos, mentais, auditivos, visuais, entre outros, é uma discussão que sempre traz certa polêmica. Mesmo com os direitos que a legislação garante, busca-se entender até que ponto a inclusão dessas pessoas ocorre concretamente, trazendo benefícios para elas, uma vez que muitos profissionais da educação ainda não estão preparados para lidar com essa nova demanda educativa. Será que o mais adequado seria interá-las em espaços específicos e destinados à Educação Especial como fazem alguns pais? Ou, apesar das falhas, o mais correto seria incluí-las e mantê-las integradas aos ambientes de ensino regular? De que forma pode-se garantir uma significativa aprendizagem a essas pessoas? Quem são os responsáveis para tal?

De acordo com o Ministério da Educação, com base nos dados disponibilizados pelo Instituto Brasileiro de Educação e Estatística (IBGE) no ano de
$2000,14,4 \%$ da população brasileira possuía algum tipo de deficiência, sendo que, distribuindo tal porcentagem pelas regiões desse país, o maior índice encontrava-se na região Sudeste com 5,6\% seguida da região Nordeste com $4,7 \%$, como pode ser verificado na Figura 1.

$\mathrm{Na}$ realidade, o que se pretende com os números apresentados na Figura 1 não é apenas apontar dados estatísticos, mas mostrar que esse total de $14,4 \%$ significa que, naquele ano, mais ou menos 24.600.256 pessoas necessitavam (ou ainda necessitam) de atenção e cuidado de acordo com a deficiência específica de cada uma. O censo apresenta ainda que desse total, 16.644 .842 pessoas possuíam deficiência do tipo visual, ou seja, mais da metade dos deficientes existentes no Brasil são incapazes ou possuem dificuldade permanente de enxergar. Sendo assim, esses dados permitem ter uma noção do número de deficientes existentes no Brasil e refletir sobre a forma com que estas pessoas foram ou estão sendo educadas. Receberam ou estão recebendo uma atenção necessária à sua formação? De que forma a família, a sociedade, o Estado contribui para incluí-los não só no ambiente escolar como também em outros espaços sociais?

Percebe-se que, quando se trata da inclusão de pessoas com Necessidades Educativas Especiais, muitas dúvidas ainda perpassam. Mesmo com as leis e direitos assegurados pela legislação, sabe-se que muito ainda deve ser feito para garantir uma verdadeira inclusão e uma significativa educação, exigindo, antes de tudo, o conhecimento desses direitos para que se possa agir em prol do melhor e mais adequado para estes cidadãos.

É relevante então lembrar ou informar que a Constituição de 1988 garantiu, nos seus Artigos 205, 206 e 208-III, que a educação é dever do Estado e da família e direito de todos, e assegurou a igualdade de condições para o acesso e permanência na escola, sendo que esta deve estender-se ao atendimento aos deficientes, com preferência na rede regular de ensino (BRASIL, 1988). Além disso, a Lei de Diretrizes e Bases 9.394/96, no artigo 59-I, apresenta que "os sistemas de ensino devem garantir a essas pessoas currículos, métodos, recursos didáticos e organização específicos, para atender às suas necessidades" (BRASIL, 1999, p.51). 


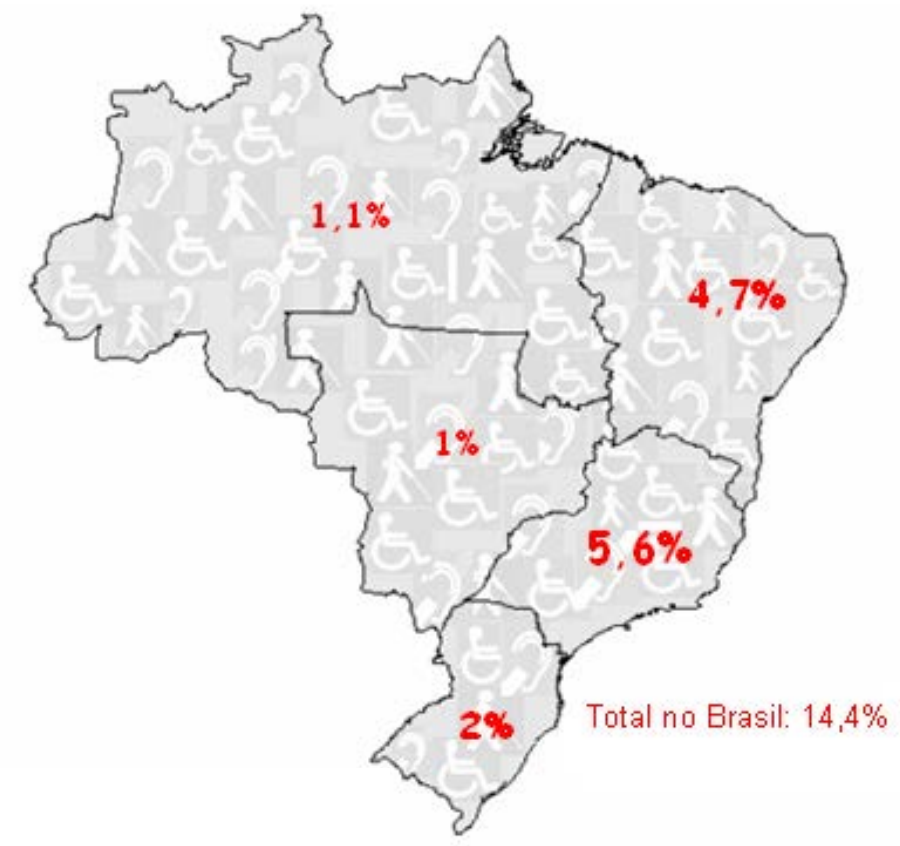

Figura 1: Porcentagem de pessoas com algum tipo de deficiência no Brasil por Região em 2000 Fonte:Ministério da Educação, 2000. Elaboração: CAMPOS, M. C.; Jan. 2014.

Entretanto, levando em conta esses e outros direitos que trazem, por sua vez, um grande avanço na Educação Especial e fazem com que se verifique uma inserção maior dessas pessoas nas escolas, ainda há uma preocupação em saber como esses espaços estão sendo preparados para recebê-las. E, quando se trata da inclusão de alunos com Deficiência Visual, essa preparação se faz ainda mais minuciosa tanto no espaço físico como no atendimento e comportamento dos integrantes desse ambiente interno.

Direcionando para o ensino, esse contexto permite fazer alguns questionamentos: Será que os professores estão preparados para trabalhar com alunos com Necessidades Educativas Especiais? E quanto ao ensino da Geografia, como os professores vêm trabalhando com os mesmos? Durante a organização de suas atividades utilizam recursos cartográficos? Os alunos têm acesso e dominam a Cartografia? É utilizada superficialmente? Como estão ensinando o espaço geográfico que esses alunos estão inseridos? É com base nesses e outros questionamentos que esse trabalho vem para auxiliar a desvendar alguns métodos e estratégias relacionados com o ensino da Cartografia, buscando dar suporte aos professores de Geografia que possuem na escola discentes com Deficiência Visual.

\section{O PAPEL DO PROFESSOR DE GEOGRAFIA, O DEFICIENTE VISUAL E A APRENDIZADEM DA CARTOGRAFIA TÁTIL}

Muitos professores de Geografia encontram dificuldades para trabalhar a Cartografia nas aulas com alunos não deficientes, seja por falta de preparação e de recursos ou até mesmo pela falta de domínio e conhecimento da linguagem cartográfica. No que diz respeito à educação de alunos com Deficiência Visual, o grau de complexidade se torna ainda maior no ensino da disciplina em questão, uma vez que a maioria desses professores não estão preparados para se relacionar com os mesmos e desconhecem metodologias de trabalho voltadas para tal. Pode-se inferir, então, que a pouca disponibilidade de recursos e o despreparo do professor comprometem a formação de conceitos e das representações espaciais, a mobilidade, a orientação e autonomia desses alunos.

Assim, o ensino da Cartografia e o trabalho 
com recursos cartográficos para deficientes visuais são, na maioria das vezes, negligenciados pelos professores de Geografia, fazendo com que ocorra o excesso da transmissão de informações, limitando a aprendizagem dessas pessoas apenas à memorização. Os professores desprezam também "[...] toda ou qualquer iniciativa que o aluno possa vir a ter, promovendo não só a exclusão, como também a falta de vontade em realizar atividades" (ROSSI, 2000, p.59), o que, conseqüentemente, faz com que esses alunos se considerem incapazes e inferiores aos demais.

Diante da importância da educação de todo e qualquer cidadão, do valor da aprendizagem da Geografia e da Cartografia, da exigência nas mudanças das metodologias de ensino, das garantias educativas asseguradas a todos nos documentos oficiais', não é mais admissível que os profissionais da educação atuem de forma discriminatória e preconceituosa, excluindo os alunos do direito ao acesso às questões educativas. Faz-se imperativo que, além das características gerais requeridas, o professor domine habilidades específicas e seja competente para o bom andamento do trabalho, fornecendo subsídios para que os alunos com Deficiência Visual explorem mais o meio em que vivem (VENTORINI e FREITAS, 2003).

\section{A Deficiência Visual nada mais é do que}

[...] a perda total da visão, pode ser adquirida, ou congênita (desde o nascimento). $O$ indivíduo que nasce com o sentido da visão, perdendo-o mais tarde, guarda memórias visuais, consegue se lembrar das imagens, luzes e cores que conheceu, e isso é muito útil para sua readaptação. Quem nasce sem a capacidade da visão, por outro lado, jamais pode formar uma memória visual, possuir lembranças visuais (MARTA GIL, 2000, p.08).

Nessa lógica, a deficiência visual não representa um empecilho ao processo de aprendizagem e ao desenvolvimento intelectual das pessoas que a possui, tornando-se necessário elaborar métodos de ensino que trabalhem, por vias alternativas, as informações que não podem ser obtidas por meio da visão.

Em vista disso, como afirma Miura (1999), o professor deve proporcionar experiências necessárias à superação de determinadas dificuldades decorrentes de sua limitação e oferecer o apoio essencial à manutenção do nível de aprendizagem compatível com o da turma a que pertence. Ele precisa saber como se relacionar com seus alunos, selecionar e desenvolver atividades que tragam momentos contínuos de interação, respeito, compreensão e solidariedade entre todos os envolvidos, o que auxilia que os indivíduos se desenvolvam dentro desse espaço, interagindo com os que estão a sua volta.

Nessa perspectiva, os professores de Geografia precisam perceber que a Cartografia é uma ferramenta fundamental que pode auxiliar demasiadamente as suas aulas, já que se baseia na leitura, interpretação, análise e representação dos diversos recortes do espaço, sendo, por isso, imprescindível a compreensão de que

[...] a Geografia como uma ciência que estuda as relações entre o homem, a natureza e a sociedade, necessita, além de um embasamento teórico consistente, de instrumentos técnicos adequados. E, como um dos principais instrumentos técnicos da geografia é a representação cartográfica dos eventos e processos da superfície terrestre, há necessidade que o cidadão aprenda a ler, interpretar e analisar mapas, cartas, plantas e outros (SIEGLER e MELLO, 1985 apud MOREIRA, 2004, p.11).

Tendo apreendido a seriedade e necessidade da utilização dos recursos cartográficos, podemos ter como resultado a noção da dimensão dos nossos espaços, o domínio de conceitos, a visão crítica e consciente dos fenômenos do espaço geográfico, o que exige que esses recursos sejam disponibilizados e acessíveis a todos, porém, adaptados para os cidadãos com Deficiência Visual.

Sendo assim, diante das dificuldades que os professores de Geografia possuem em encontrar metodologias relacionadas ao trabalho com o deficiente visual e, levando em conta também que muitos não abordam os conhecimentos cartográficos, a Cartografia Tátil aparece exatamente para promover ideias e sugestões de atividades que garantam a esses alunos um conhecimento dos seus espaços cotidianos, sejam estes em escala local ou global.

Esse tipo de Cartografia é responsável pela adaptação de produtos cartográficos convencionais em materiais destinados às pessoas com Deficiência Visual (LOCH, 2008), sendo necessário, entretanto, obedecer a alguns critérios de elaboração e utilização, levando em conta, principalmente, a idade, a série, o nível de desenvolvimento cognitivo e a ma- 
turidade tanto dos alunos quanto da própria turma, para que dessa forma sirvam realmente como aliados à aprendizagem.

A Cartografia tátil se preocupa com a confecção de mapas e instrumentos cartográficos para pessoas cegas ou com baixa visão, possibilitando uma maior percepção do mundo, a ampliação da percepção e facilitando a mobilidade, transformando-se em uma importante ferramenta para o ensino de Geografia e outras disciplinas.

Sugere-se, por exemplo, a construção de maquetes, gráficos, tabelas, mapas táteis e outros recursos cartográficos, sendo fundamental, também, a análise e interpretação dos mesmos, já que, sem isso, não é possível fazer com que os alunos com Deficiência Visual compreendam a distribuição e organização dos espaços, perdendo, portanto, o sentido das atividades. É importante considerar ainda que

[...] cada pessoa desenvolve processos particulares de codificação que formam imagens mentais. A habilidade para compreender, interpretar e assimilar a informação será ampliada de acordo com a pluralidade das experiências, a variedade e qualidade do material, a clareza, a simplicidade e a forma como o comportamento exploratório é estimulado e desenvolvido (CAMPOS, 2007, p.16).

Direcionando e enfatizando os mapas táteis, um dos principais produtos da Cartografia Tátil, sua elaboração deve ser feita a partir de mapas convencionais, sendo, por isso, essencial escolher mapas-base de acordo com os propósitos de uso e as necessidades dos usuários. Eles são importantes instrumentos de inclusão social, por meio da percepção espacial e contribuindo para o aprendizado desses alunos. São representações gráficas que devem ser formados por meio de diferentes texturas (como apresentado na Figura 2) ou em alto relevo, contendo informações que possam ser lidas pelos indivíduos com Deficiência Visual.

\section{Assim, é importante ressaltar que}

o relevo deve ser facilmente percebido pelo tato e, sempre que possível, constituir-se de diferentes texturas para

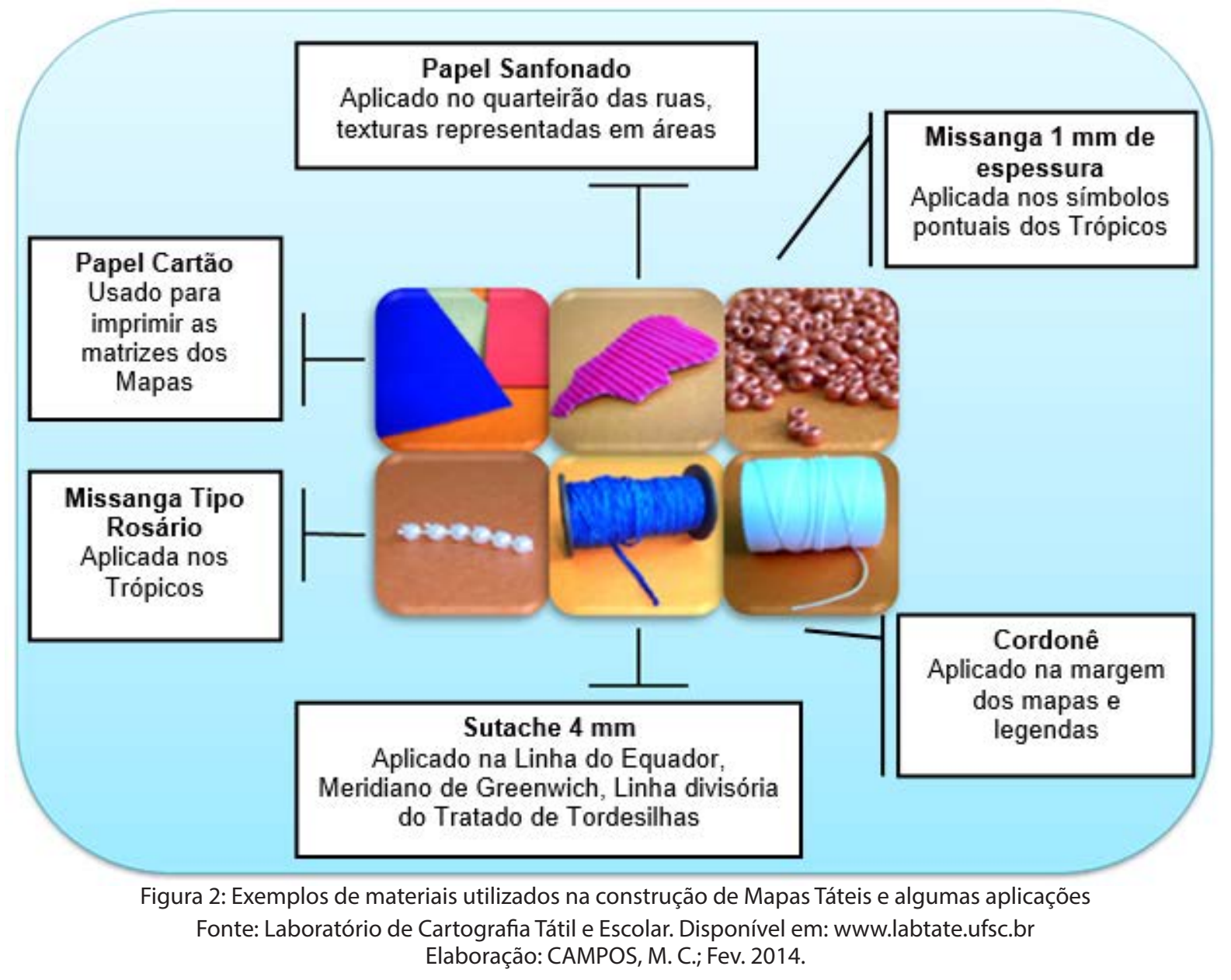

Geografia, Ensino \& Pesquisa, Vol. 20 (2016), n.1, p. 95-102

ISSN: 2236-4994 DOI: 10.5902/2236499414389 
melhor destacar as partes componentes do todo. Contrastes do tipo liso/áspero, fino/espesso, permitem distinções adequadas. O material não deve provocar rejeição ao manuseio e ser resistente para que não se estrague com facilidade e resista à exploração tátil e ao manuseio constante. Deve ser simples e de manuseio fácil, proporcionando uma prática utilização e não deve oferecer perigo para os alunos (CAMPOS, 2007, p.27)

Dessa forma, na elaboração dos mapas táteis, não é recomendada a utilização de grandes quantidades de informações, já que os detalhes adquiridos pelo tato não são captados tão facilmente como os alcançados pela visão, sendo aconselhável, então, a confecção de mapas táteis temáticos, ou seja, mapas que representem apenas um único tema. É importante, ainda, que os elementos do mapa, como título, legenda, fonte, escala, estejam organizados e escritos convencionalmente e em Braille, e que as texturas sejam agradáveis ao toque, diferenciando, assim, os dados que serão representados e decodificados/ interpretados por esses alunos. As Figuras 3 e 4 trazem alguns exemplos de mapas táteis.

O professor pode, ainda, a partir de tais construções, confeccionar atlas geográficos contendo os mais variados temas e representações seja, por exemplo, dos bairros existentes na cidade dos alunos, das microrregiões da Bahia, das bacias hidrográficas brasileiras, dos tipos de clima existentes nesse ou em outros países, etc.

Assim, com essas (e outras) experiências, os alunos com Deficiência Visual poderão ir adquirindo, gradualmente, uma compreensão geográfica do mundo, ampliando suas percepções espaciais,

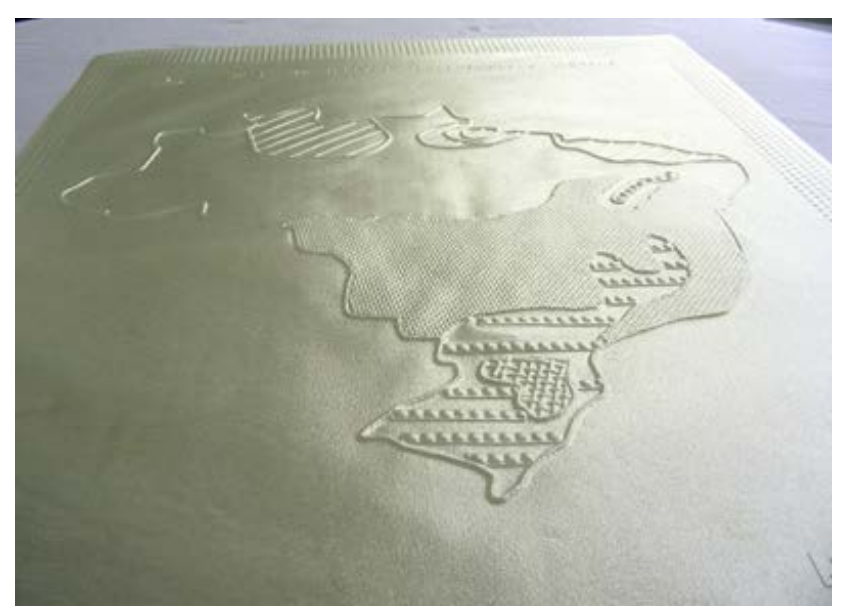

Figura 3: Mapa tátil.

Fonte: Laboratório de Cartografia Tátil e Escolar (LABTATE). Disponível em: www.labtate.ufsc.br

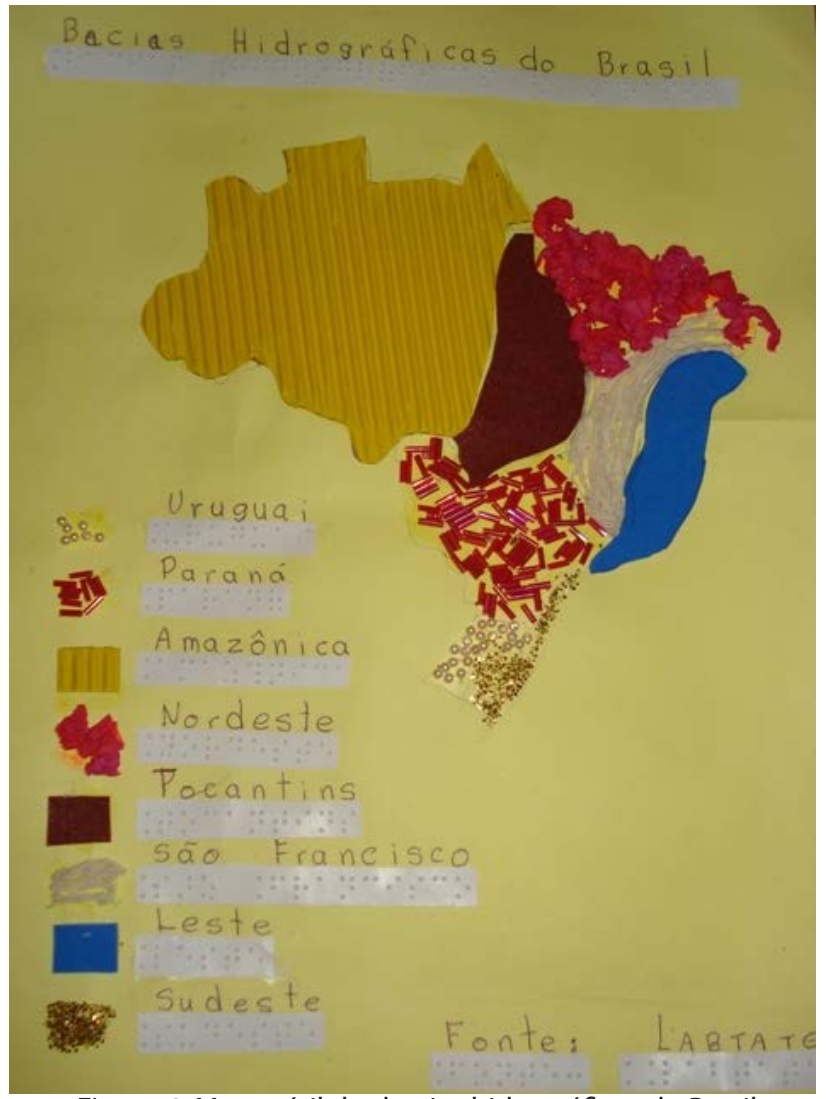

Figura 4: Mapa tátil das bacias hidrográficas do Brasil

Fonte: Laboratório de Cartografia Tátil e Escolar (LABTATE). Disponível em: www.labtate.ufsc.br. Elaboração: CAMPOS, M. C.; Fev. 2014.

o que, conseqüentemente, tornará mais fácil a sua mobilidade nos mais variados espaços sociais. Daí a responsabilidade do professor em mediar o uso dos recursos e as atividades, incentivando a participação e promovendo a criatividade de todos os envolvidos, sendo possível, a partir disso, promover o acesso e a inclusão do cidadão com Deficiência Visual e não o seu distanciamento nas atividades e nas aulas de Geografia.

\section{CONSIDERAÇÕES FINAIS}

As ideias apresentadas nesse trabalho não admitem conclusões ou pensamentos prontos e acabados, mas convidam para um diálogo em que as discussões e as sugestões não se encerram, ao contrário, se ampliam. Entender a realidade pela qual os alunos com Necessidades Educativas Especiais estão suscetíveis e, em especial, os com Deficiência Visual, é fundamental para pensar em mudanças que pos- 
sam trazer verdadeiramente a inclusão dos mesmos. É preciso expor uma preocupação voltada à eliminação do cotidiano de preconceito e da exclusão que é visível na maioria dos espaços sociais, inclusive nas escolas, o que é possível não apenas com leis específicas, mas com o apoio da família, da escola, da sociedade por meio de atitudes que perpassem pela promoção do melhor para os mesmos.

No que se refere ao ensino, essas atitudes devem partir de todos os integrantes da escola e precisam estar direcionadas à preparação de aulas e atividades que propiciem uma aprendizagem significativa, fugindo das práticas que ignorem os Deficientes Visuais e os tornem incapazes de participar e realizar as atividades. Essa aprendizagem é plausível somente através do respeito às diferenças - já que cada pessoa, com ou sem necessidades especiais, é diferente - da atenção com os mesmos, da promoção de situações constantes de inclusão e da motivação para o desenvolvimento de suas habilidades.

Especificando ainda as aulas de Geografia, os professores podem e devem ministrar aulas estimulantes e atraentes aproveitando-se dos benefícios que a Cartografia pode trazer, claro que, para isso, precisando estar preparados e capacitados. Necessitam, então, não apenas de conhecimento teórico na área, mas também de experiências e métodos que busquem abarcar todos os sujeitos e focalizar as vivências dos mesmos, enriquecendo e (re)formulando as reflexões destes acerca das noções e dimensões do espaço geográfico.

O professor precisa também estar ciente que a ausência da visão faz com que as pessoas com Deficiência Visual possuam outros sentidos compensatórios, principalmente a audição e o tato, o que demanda todo um planejamento voltado para tal. Dessa forma, aprender e ensinar Braille (sistema de escrita e impressão para cegos), propiciar exercícios que exijam concentração, trabalho com texturas, são alguns exemplos de atividades que exploram o desenvolvimento desses sentidos fazendo com que, aos poucos, eles possam ir aprendendo e amadurecendo por meio dessas (e de outras) experiências.

Nessa lógica, o ensino de Geografia pode contribuir para a formação de alunos participativos, capazes de acompanhar e intervir criticamente na realidade em que vivem à medida que propicia o entendimento do espaço geográfico. Pode-se alcançar essa formação através da utilização de práticas pedagógicas que contribuam para o sucesso dos alunos com e sem Deficiência Visual, como, por exemplo, práticas que tenham como suporte os recursos cartográficos, uma vez que fornecem o dinamismo, a criatividade e também o desenvolvimento da capacidade de raciocínio, análise e interpretação do espaço em que vivem.

Deve-se então considerar a relevância do ensino da Cartografia Tátil para alunos com Deficiência Visual, pois será uma forma de proporcionar-lhes maior facilidade na aprendizagem e melhor condição de vida, haja vista que, a partir desta prática, eles terão maior agilidade na locomoção e melhor compreensão de sua inserção no espaço.

\section{REFERÊNCIAS BIBLIOGRÁFICAS}

BRASIL. Secretaria de Educação Média e Tecnológica. Parâmetros Curriculares Nacionais: Ensino Médio. Brasília: MEC, 1999.

BRASIL. Constituição da República Federativa do Brasil de 1988. Disponível em http://www.senado.gov.br/ sf/legislacao/const/. Acesso em: 08 mar. 2014.

CAMPOS, Izilda Maria de; SILVA, Myriam Beatriz Campolina. Atendimento Educacional Especializado: Deficiência Visual. Brasília: SEEP/SEED/MEC, 2007.

IBGE. Censo demográfico de 2000. Disponível em http://www.sidra.ibge.gov.br. Acesso em: 08 mar. 2014.

LABTATE, Laboratório de Cartografia Tátil e Escolar. O que são Mapas táteis? Disponível em: http://www. labtate.ufsc.br/ct_mapas_tateis.htm. Acesso em: 07 fev. 2014.

LOCH, Ruth Emilia Nogueira. Cartografia Tátil: mapas para deficientes visuais. Londrina, v.1, n.1, maio/ ago., p.35-58, 2008. Disponível em: http://www.uel. $\mathrm{br} /$ revistas/uel/index.php/portalcartografia. Acesso em: 07 fev. 2014.

MARTA GIL (org.). Deficiência visual - Brasília: MEC. Secretaria de Educação a Distância, 2000. Disponível em: <http://portal.mec.gov.br/seed/arquivos/ 
pdf/ deficienciavisual.pdf> Acesso em 08 mar. 2014.

MINISTÉRIO DA EDUCAÇÃO. Dados da Educação Especial. Disponível em http://portal.mec.gov.br/seesp/ index.php?option $=$ content\&task=view\&id=62\&ltemid=191. Acesso em: 13 mar. 2014.

MIURA, Regina Keiko Kato. Educação Especial: Formação de Professores, ensino e integração. Cadernos da FFC. UNESP: Marília, v. 8, n. 1, p. 39-54, 1999.

MOREIRA, Suely. Linguagem Cartográfica e prática docente na rede municipal de ensino de Uberlândia - MG. Universidade Federal de Uberlândia, 2004.

ROSSI, Dariane. Deficiência Visual: desafios para o ensino especial e a geografia em sala de aula. IN: REGO, Nelson; SUERTEGARAY, Dirce Maria; HEIDRI$\mathrm{CH}$, Alvaro Luiz. Geografia e Educação: geração de ambiências. Porto Alegre: Ed. Universidade/ UFRGS, p.57- 65, 2000.

VENTORINI, Sílvia Elena; FREITAS, Maria Isabel Castreghini. Cartografia Tátil: Pesquisa e Perspectiva no desenvolvimento de material didático tátil. UNESP: Departamento de Planejamento Territorial e Geoprocessamento, 2003.

Notas de Fim:

1- Encontrado na Declaração de Salamanca, Constituição Federal, LDB 9394/96 e outros.

Correspondência da autora:

Mariluze de Carvalho Campos e-mail: luze.carvalho@gmail.com

Artigo recebido em: 16/06/2014

Revisado pela autora em: 14/10/2015

Aceito para publicação em: 11/11/2015

Geografia, Ensino \& Pesquisa, Vol. 20 (2016), n.1, p. 95-102

ISSN: 2236-4994 DOI: 10.5902/2236499414389 